\title{
Interfaces no processo de mediação em teletandem português e espanhol: o papel dos mediadores
}

DOI: http://dx.doi.org/10.21165/el.v48i2.2262

\section{Kelly Cristiane Henschel Pobbe de Carvalho' Karin Adriane Henschel Pobbe Ramos ${ }^{2}$}

\section{Resumo}

A prática de teletandem em contexto de línguas próximas, como o português e o espanhol, traz algumas especificidades que são inerentes ao processo, tais como, a possibilidade de intercomunicação entre os interagentes. Nesse caso, é necessário observar mais atentamente o papel do mediador na supervisão e acompanhamento de tais interações, de maneira a considerar a relevância dos aspectos linguísticos e culturais. Essa observação pode ser feita por meio de monitoramento constante dos estudantes pelo mediador, como um modo de estimular a conscientização linguística e intercultural. Neste trabalho, temos como objetivo descrever as ações decorrentes desse processo de mediação compreendido de forma mais ampla - que inclui desde os primeiros contatos com as instituições estrangeiras à organização, acompanhamento, supervisão e avaliação -, bem como discutir alguns pressupostos teóricos que podem servir de subsídio ao aprimoramento dessa prática, a partir da perspectiva metodológica da teoria fundamentada (CHARMAZ, 2009). Apresentamos algumas estratégias para esse processo, a partir de nossa experiência na mediação em interações de teletandem português e espanhol, em uma parceria entre uma universidade brasileira e uma universidade mexicana. Nossas análises demonstram que os princípios de autonomia e de reciprocidade (TELLES; VASSALO, 2006) da aprendizagem em tandem estão diretamente relacionados com o processo de mediação e contribuem para a constituição de um contexto profícuo de ensino e aprendizagem de línguas.

Palavras-chave: Teletandem; línguas próximas; mediação.

\footnotetext{
1 Universidade Estadual Paulista (UNESP), Assis, SP, Brasil; kelly.carvalho@unesp.br; https://orcid.org/0000-0001-6115-3367

2 Universidade Estadual Paulista (UNESP), Assis, SP, Brasil; karin.ramos@unesp.br; https://orcid.org/0000-0002-9850-1393
} 


\title{
Interfaces in the mediation process for Portuguese and Spanish Teletandem: the role of mediators
}

\begin{abstract}
The practice of Teletandem within contexts of close languages, such as Portuguese and Spanish, has peculiarities that are inherent to the process such as the possibility of intercommunication between the pairs. Even though this intercommunication can occur in other pairs, in close languages it becomes more evident. In this case, it is necessary to observe the process of mediation more closely and consider the relevance of cultural and linguistic aspects. Such observation can be done through constant monitoring of the students by the mediator as a way to stimulate language and intercultural awareness. In this paper, we aim to describe the actions that occur during the mediation process - that includes since the first contacts with the partner institutions to the organization, supervision and evaluation -, as well as to discuss some theoretical assumptions that can provide support and improve this practice from the methodological perspective of grounded theory (CHARMAZ, 2009). We also outline some strategies for this process, based on our experience as mediators in Portuguese and Spanish teletandem interactions between a Brazilian and a Mexican university. Our analyses suggest that the principles of autonomy and reciprocity (TELLES; VASSALO, 2006) of tandem learning are directly related to the mediation process and they contribute to an effective collaborative context of language teaching and learning.
\end{abstract}

Keywords: Teletandem; close languages; mediation.

\section{Introdução}

Em nossa trajetória acadêmica, já há algum tempo compartilhada por meio do grupo de pesquisa ${ }^{3}$, participamos ativamente das atividades no âmbito do projeto Teletandem Brasil: línguas estrangeiras para todos ${ }^{4}$, em nossa instituição. Nesse percurso, vimos acompanhando a forma como o projeto se redesenhou devido às novas demandas decorrentes de seu próprio desenvolvimento, conforme veremos adiante.

Neste trabalho, temos como objetivo, portanto, descrever as ações integrantes do processo de mediação nesse contexto, compreendido de forma mais ampla (que se

3 Teletandem: Transculturalidade das interações on-line via webcam. http://dgp.cnpq.br/dgp/ espelhogrupo/14830

4 Teletandem Brasil: línguas estrangeiras para todos é um projeto temático desenvolvido com o apoio da FAPESP - Processo 2006/03204-2, http://www.teletandembrasil.org. Em versão atual, o projeto é intitulado: Teletandem: Transculturalidade na Comunicação On-line em Línguas Estrangeiras por Webcam. 
inicia desde os primeiros contatos com as instituições estrangeiras e se estende à organização, acompanhamento, supervisão e avaliação), bem como discutir sobre alguns pressupostos teóricos que podem servir de subsídio para o aprimoramento dessa prática e para a implementação do teletandem em outras instituições. Para tanto, partiremos da nossa experiência na mediação em interações de teletandem português e espanhol que desenvolvemos em parceria com uma universidade mexicana, já há alguns anos.

Em estudo anterior (RAMOS; CARVALHO; MESSIAS, 2013), já assinalamos que a prática do teletandem entre línguas próximas, tais como, o português e o espanhol, apresenta algumas especificidades que the são inerentes, relacionadas à possibilidade natural de haver certo grau de intercomunicação entre os pares de interagentes. Nesse caso, além dos aspectos gerais (também comuns em interações em outras línguas) a serem considerados no processo de mediação no teletandem, é necessário observar mais atentamente o papel do mediador na supervisão e acompanhamento em tais interações, de maneira a estimular a conscientização linguística e intercultural por parte dos participantes, conforme pontuamos:

\begin{abstract}
[...] as práticas de Teletandem funcionam quando pensamos na relação ou contato entre línguas próximas, tais como o português e o espanhol, desde que exista comprometimento dos parceiros e das instituições envolvidas, domínio e conhecimento das línguas e um monitoramento por parte dos professores mediadores, de maneira a estimular a conscientização sobre as deficiências e debilidades com relação ao uso da língua entre os alunos envolvidos. Dessa forma, o contexto virtual do Teletandem pode ser um ambiente de práticas discursivas que contribui para o desenvolvimento da autonomia, da responsabilidade e do compromisso dos aprendizes, levando-os a uma conscientização crítica sobre sua língua e sua cultura. (RAMOS, CARVALHO, MESSIAS, 2013, p. 19).
\end{abstract}

Para cumprir os objetivos propostos, apresentamos, metodologicamente, a partir da experiência aqui considerada, os movimentos acionados na constituição do processo de mediação no teletandem em suas diversas perspectivas, as quais mobilizam um percurso de ações que são realizadas antes, durante e após o seu desenvolvimento, conforme seguem: (1) a mediação e a interface entre mediadores e instituições; (2) a mediação e a interface entre mediadores; (3) a mediação e a interface entre mediadores e interagentes; e, finalmente, (4) a mediação de teletandem entre línguas próximas (português/espanhol).

Para tanto, valemo-nos de uma perspectiva metodológica ancorada na teoria fundamentada (CHARMAZ, 2009), cujos métodos estão baseados na coleta sistemática de dados os quais, após a análise, dão origem a conceitos. Essa perspectiva começa pelos dados, construídos por meio de observações, interações e materiais organizados 
segundo os objetivos da pesquisa. A partir dessa sistematização, são estudadas as experiências e os eventos empíricos, conforme as possibilidades analíticas que se apresentam. De acordo com Charmaz (2009), a reflexão culmina em uma compreensão teórica da experiência estudada. Os dados que dão origem às teorizações aqui empreendidas são oriundos de memorandos produzidos a partir de nossa experiência de gerenciamento das sessões de interação de teletandem e condução das sessões de mediação.

É importante salientar que os pressupostos teóricos que norteiam a descrição e discussão aqui propostas estão alicerçados nos princípios socioconstrutivistas de que o aprendizado de línguas estrangeiras, no caso, se dá por meio da interação entre pessoas e com o ambiente, em uma relação de cooperação (VYGOTSKI, 2007). Esses princípios permitem compreender o desenvolvimento sociocognitivo do ser humano e também fundamentam as recentes tendências para o ensino de línguas estrangeiras, menos artificializadas e mais naturais e humanas, mais comunicativas e baseadas na experiência prática em ambientes transculturais de convívio, inclusive os contextos tecnológicos.

\title{
Teletandem: a instituição do processo de mediação
}

A proposta inicial do projeto surgiu como uma iniciativa para democratização do acesso a línguas estrangeiras, estabelecendo parcerias entre estudantes universitários brasileiros e de universidades estrangeiras, em um contexto virtual de aprendizagem autônoma e colaborativa em que cada um ensina sua língua de proficiência e, ao mesmo tempo, aprende a língua do outro, mediante o uso de ferramentas de conversa e/ou mensagem instantânea (TELLES, 2009; TELLES; VASSALO, 2006). Outros autores o definem como um "modelo de aprendizagem", conforme observamos a seguir:

\begin{abstract}
Trata-se do regime de tandem, um modelo de aprendizagem colaborativa de línguas surgido no final do século passado que, em sua versão mais atual, o teletandem, faz uso de aplicativos de mensagens instantâneas (Instant Messaging) para o contato virtual entre aprendizes de línguas estrangeiras (LE). (BENEDETTI, 2013, p. 66).
\end{abstract}

Mais recentemente, um dos aspectos que passa a ser considerado no escopo das pesquisas sobre o teletandem é o "contato transcultural" instaurado em tais interações. Dessa forma, em nova edição do projeto, o teletandem é redefinido como:

[...] uma forma de telecolaboração - um contexto virtual, colaborativo e autônomo para aprendizagem de línguas estrangeiras, no qual dois estudantes ajudam-se mutuamente para aprender a língua um do 
outro (ou a língua de proficiência). Eles utilizam recursos tecnológicos de texto, voz e webcam (tais como Skype), adotando os três princípios de aprendizagem em tendem: autonomia, reciprocidade e separação entre as línguas. (TELLES, 2015, p. 652, tradução nossa5).

É importante explicitar que o processo de ensino e aprendizagem no teletandem, desde sempre, está baseado em princípios de autonomia e reciprocidade compartilhados pela parceria. Não se trata de uma simples conversa entre um par bilíngue; os participantes no teletandem são pessoas interessadas em aprender a língua do outro, a distância e de forma relativamente autônoma (TELLES, 2009).

Ao longo desses anos, muitas transformações ocorreram no que diz respeito também ao formato e efetivação das parcerias e à maneira como as sessões vêm sendo conduzidas. Inicialmente, as interações ocorriam de forma independente, em horários acordados entre os próprios interagentes, de forma mais autônoma. De acordo com Aranha e Cavalari (2014, p. 184), o teletandem surge facilitado pela tecnologia como uma "forma de promover o ensino-aprendizagem de línguas estrangeiras por meio de encontros regulares e virtuais entre pares de falantes de línguas diferentes que vivem em países diferentes". Atualmente, as interações acontecem em grupos, nos laboratórios das universidades, em horários estabelecidos por professores e/ou alunos de pós-graduação, os quais passaram a atuar como mediadores do processo, coordenando, organizando e acompanhando as sessões.

Assim sendo, o diferencial das práticas de teletandem em grupos na universidade reside na forma de condução das atividades: se integram ou não o horário das aulas regulares, e se tais atividades estão vinculadas ou não às disciplinas de línguas estrangeiras. Segundo Telles (2009), tais experiências configuram-se no modelo Institucional, pois são acordadas entre duas universidades, com certo controle pedagógico e com diretrizes estabelecidas. Quando as interações são, ainda, concomitantes às aulas, configuradas como atividades obrigatórias de disciplinas curriculares, estabelece-se o modelo de Teletandem Institucional Integrado (ARANHA; CAVALARI, 2014). Em alguns casos, o teletandem pode ainda constituir atividade voluntária, em geral, certificada como horas de atividades complementares ou contabilizado como horas de prática de laboratório de línguas.

5 No original: "[...] a mode of telecollaboration - a virtual, collaborative and autonomous context for learning foreign languages in which two students help each other to learn their own languages (or language of proficiency). They do so by using the text, voice and webcam image resources of VOIP technology (such as Skype), and by adopting the three principles of tandem learning: autonomy, reciprocity, and separate use of both languages.". 
Esse modelo organizacional modificou-se à medida que novas parcerias entre nossa universidade e universidades estrangeiras foram concretizadas. Dessa forma, os objetivos desse novo formato também se expandiram em relação ao modelo anterior. Por um lado, a modalidade em grupos passa a existir para atender às demandas de universidades estrangeiras com interesse em incluir a prática do teletandem como parte das atividades dos alunos nas aulas regulares de português como língua estrangeira. Por outro lado, essa nova configuração também significa, em nossa instituição, constituir um novo espaço (além da sala de aula) que não apenas possibilita a inserção dos alunos em contextos autênticos de comunicação em língua estrangeira, mas também o compartilhamento de suas experiências para uma formação crítico-reflexiva.

Esse espaço é constituído, portanto, pelas sessões de interação e pelas sessões de mediação: após cada sessão de interação são organizadas as mediações, momento em que se abre espaço para que os participantes relatem e compartilhem suas experiências. Nesse contexto, cabe aos mediadores buscar formas de intervenção para auxiliar na potencialização do processo de ensino e aprendizagem proposto pelo teletandem. Conforme Telles (2015, p. 655, tradução nossa ${ }^{6}$ ),

\begin{abstract}
Sessões de mediação são conduzidas pelos professores após cada sessão de teletandem. Eles enfocam aspectos das línguas-alvo, os processos de aprendizagem dos estudantes e os aspectos culturais que emergem (implícita ou explicitamente) durante as interações. Sessões de mediação podem ser conduzidas tanto na língua materna quanto na língua-alvo, conforme o nível dos estudantes. A prática de conduzir sessões de mediação em teletandem exige conhecimentos sobre contato intercultural, discurso e comunicação.
\end{abstract}

No acompanhamento das atividades de teletandem, temos observado, no entanto, que as atribuições dos mediadores não se restringem apenas ao acompanhamento das sessões; de certa forma, suas tarefas se ampliaram. Os mediadores passaram a desempenhar diferentes funções no gerenciamento e supervisão, e no desenvolvimento de pesquisa e ensino. São professores da graduação e/ou alunos da pós-graduação e da graduação que atuam desde o estabelecimento inicial das parcerias com universidades estrangeiras até a organização e supervisão das sessões de interação e mediação, em seus múltiplos aspectos, tais como orientações quanto ao uso das ferramentas tecnológicas, orientações de natureza linguístico-cultural, negociações entre pares de interagentes etc.

6 No original: "Mediation sessions are conducted by the teachers after each teletandem session. They focus on aspects of the target languages, the students' learning processes and the cultural aspects and themes that emerge (implicitly or explicitly) during the interactions. Mediation sessions can be conducted in either the native or target language, depending on the students' level in the latter. The practice of conducting teletandem mediation sessions requires knowledge about intercultural contact, discourse and communication". 
A mediação, portanto, é compreendida aqui como um processo de caráter mais amplo que, embora inclua a sessão de mediação em seu sentido mais estrito, segundo descrito por Telles (2015), engloba outros procedimentos. Trata-se de todo um processo que se inicia nos primeiros contatos com as instituições estrangeiras e se estende à organização, acompanhamento, supervisão e avaliação.

Para Ramos (2013), esse controle instaurado por essa nova configuração, em certa medida, tem repercussão direta nos princípios de autonomia e de reciprocidade os quais definem o teletandem. Entretanto, sem a presença de um mediador (como ocorre no modelo independente), embora os parceiros tenham muito mais autonomia, os níveis de responsabilidade variam de acordo com as características dos interagentes, o que pode tornar o processo mais instável e menos duradouro.

Com o objetivo de descrever as ações integrantes desse processo de mediação, apresentamos a seguir alguns de seus aspectos, tomando como base as relações por ele instituídas, com o intuito não apenas de sistematizá-lo, mas especialmente de discutir sobre como o teletandem vem sendo desenvolvido em nossa instituição. Conforme já dissemos, para o desenvolvimento da discussão, nos respaldamos na experiência de parceria entre a nossa universidade (UNESP) e uma universidade mexicana (Universidad Nacional Autónoma de México - UNAM).

\section{Mediação: interface entre mediadores e instituições}

As mudanças pelas quais o projeto tem passado nestes últimos anos, já discutidas anteriormente, neste artigo, conferem às instituições um papel de suma importância não apenas no suporte logístico para o desenvolvimento do projeto, como também no apoio e fomento aos estudos que discutam as especificidades desse contexto tecnológico de ensino e aprendizagem de línguas estrangeiras.

Para que as parcerias sejam mantidas e novas parcerias sejam firmadas, o primeiro passo é um trabalho de divulgação do projeto, enfatizando suas contribuições para as instituições envolvidas, bem como esclarecendo as contrapartidas de cada uma das partes desse processo. Essa divulgação tem sido empreendida por vários meios, tais como site oficial, participação dos pesquisadores/mediadores em eventos acadêmicos, publicações científicas, visitas técnicas, grupos de pesquisa, materiais explicativos disponibilizados para os interessados.

O estabelecimento das parcerias envolve um longo processo de negociação, que compreende desde a troca de e-mails entre os responsáveis para os primeiros contatos, sessões piloto de interação para demonstração, encontros presenciais e por videoconferência para esclarecimentos a respeito dos objetivos do projeto e das ações para sua execução. 
A parceria entre nossa universidade e a universidade mexicana constitui-se um exemplo dessa relação estabelecida entre as instituições, por meio do contato e negociação entre os professores responsáveis (mediadores), numa trajetória que vem se consolidando desde o ano de 2013. Tanto de um lado como de outro, há o objetivo comum de criar espaços institucionais para promover o ensino e a aprendizagem de línguas, no caso, português e espanhol.

No contexto mexicano, as sessões de teletandem ocorrem na Mediateca ${ }^{7}$, instalada no Centro de Aprendizagem de Línguas da Universidade, que se configura como um espaço de aprendizagem autônoma direcionado a alunos de graduação, pós-graduação (em diversas áreas do conhecimento) e funcionários da universidade. Nesse caso, os alunos são orientados por assessores de línguas a desenvolver seu aprendizado autonomamente, respeitando sua forma de aprender e seus objetivos. Já no contexto brasileiro, as sessões ocorrem no Laboratório de Teletandem, com grupos de alunos, em sua maioria, oriundos do curso de Letras (Espanhol), como uma atividade extracurricular, a fim de complementar sua formação inicial como futuros professores de Espanhol.

Tal vínculo se enquadra, portanto, na modalidade de Teletandem Institucional Não-Integrado (ARANHA, CAVALARI, 2014), uma vez que as interações são acordadas entre as duas instituições, por meio dos mediadores, mas não estão necessariamente integradas ao currículo ou curso, em ambos os contextos.

Assim sendo, a organização das atividades do teletandem é definida entre os mediadores, nesse caso, uma professora de português como língua estrangeira da Mediateca e uma professora de espanhol como língua estrangeira do curso de Letras, de acordo com as disponibilidades dos grupos e das instituições.

Nessa relação institucional, os mediadores têm o papel de organizar, em seus respectivos contextos, toda a logística para as interações (GARCIA, 2015), que compreende: efetuar o agendamento dos laboratórios em suas instituições; verificar as condições dos equipamentos (computadores com aplicativos de videoconferência instalados, boa rede de conexão de internet); assim como estabelecer um calendário para as interações considerando: número de sessões, número de participantes, datas e horários, fuso horário, mudanças com o horário de verão.

É necessário também contar com o suporte técnico de funcionários da instituição, estagiários e monitores que auxiliam na manutenção dos equipamentos e nas questões relacionadas, por exemplo, com a instalação dos aplicativos e de softwares de gravação. Esse apoio é imprescindível, tendo em vista que muitos imprevistos podem acontecer durante as interações.

7 Disponível em: http://cele.unam.mx/index.php?categoria=6. 
Como podemos observar, os mediadores devem construir essa relação não apenas entre as instituições, mas também no interior das próprias instituições, considerandose que, muitas vezes, as questões relacionadas ao ensino e aprendizagem de línguas nem sempre são prioridade. É preciso que haja investimentos financeiros, por meio de editais de incentivo ao projeto e também por meio de um reconhecimento de seu valor. $\mathrm{O}$ teletandem tem se mostrado um empreendimento que traz visibilidade institucional e permite a troca de experiências e construção de saberes compartilhados entre os pesquisadores. Nesse sentido, os mediadores precisam reivindicar o reconhecimento institucional do projeto, elencando as contribuições que sua execução pode trazer para as próprias instituições.

\section{Mediação: interface entre mediadores}

Parte fundamental do processo de ensino e aprendizagem de línguas no contexto do teletandem é a relação que se estabelece entre os mediadores. No caso de instituições que mantêm diversas parcerias com universidades diferentes como é o nosso caso, há um corpo de mediadores os quais são designados para mediar os grupos, de acordo com as línguas envolvidas e com a disponibilidade de horários estabelecidos, geralmente, pelas instituições estrangeiras.

Nesse contexto, vimos acompanhando o processo de mediação na parceria aqui considerada, tendo em vista o nosso interesse pela aprendizagem de espanhol/LE e pelo ensino de português/LE em nossa instituição. Assim sendo, procuramos manter, desde as negociações iniciais (relacionadas à logística das interações), um diálogo constante com a mediadora mexicana, a fim de discutir as necessidades e as características dos grupos, considerando os objetivos de aprendizagem dos alunos interagentes bem como o nível de conhecimento da língua, além de questões de interculturalidade.

Nesse caso, os objetivos dos interagentes são bastante variados: por um lado, os alunos brasileiros buscam o teletandem para aprimorar a proficiência na língua estrangeira, e ampliar suas experiências interculturais, uma vez que estão inseridos num contexto de formação inicial de professores de espanhol; por outro lado, os alunos mexicanos desejam aprender português para executar estágios, intercâmbios, participar de cursos de pósgraduação no Brasil ou preparar-se para exames oficiais de proficiência e certificação.

Por tratar-se de uma parceria que se configura na modalidade de Teletandem Institucional Não-Integrado, conforme já apontamos, tanto para o contexto brasileiro como para o contexto mexicano, é preciso também considerar suas especificidades em relação a uma maior flexibilização e participação dos interagentes, os quais têm de adaptarse aos horários e mudanças, ao longo do semestre. Assim sendo, a relação entre os mediadores é extremamente relevante, pois muitas vezes alguns ajustes e concessões são necessários. 
Nesse sentido, outro aspecto a ser considerado é a necessidade de se estabelecer uma relação de cumplicidade entre os mediadores. Muitas vezes, no decorrer do processo, novas situações emergem demandando ajustes, que implicam tomadas de decisões. É importante enfatizar que essas decisões devem ser ponderadas em conjunto. Portanto, os mediadores devem manter um canal aberto de comunicação, para que os problemas sejam solucionados e possíveis ocorrências possam ser previstas.

Os mediadores também podem elencar temas para serem discutidos durante as interações. Esses temas têm como objetivo aprofundar os conhecimentos dos alunos sobre questões de ordem linguística, discursiva e também intercultural, a fim de que as trocas entre os interagentes ultrapassem os limites de uma simples conversa sobre questões do cotidiano. Essas questões geralmente aparecem nas primeiras interações, em que os interagentes constroem um vínculo. Entretanto, a escolha de temas estimula os estudantes a pesquisar conteúdos a respeito dos assuntos propostos bem como preparar atividades que são trazidas para a sessão.

Uma questão a ser destacada, ainda, com relação ao teletandem é que esse contexto se configura como um campo de pesquisa e, nesse sentido, muitos mediadores também desenvolvem estudos a respeito do processo de ensino e aprendizagem de línguas estrangeiras, transformando as interações e a mediação em objeto de seus trabalhos acadêmicos. Percebe-se que, quando os mediadores desenvolvem esse tipo de pesquisa, as parcerias tendem a se manter por mais tempo e de forma mais intensiva. Isso se confirma também no caso da parceria UNESP - UNAM, uma vez que as mediadoras estão envolvidas em atividades de pesquisa, o que, inclusive, já redundou em publicação de artigo científico em coautoria (CARVALHO, MESSIAS, DÍAS, 2015).

\section{Mediação: interface entre mediadores e interagentes}

Como uma modalidade de Teletandem Institucional Não-Integrado, na parceria UNESP UNAM, as interações constituem uma atividade opcional, tanto para o contexto brasileiro como para o mexicano. Assim sendo, podemos dizer que o vínculo aqui delineado está orientado por uma base que prima pela autonomia por parte dos interagentes, uma vez que são eles quem decidem participar ou não, segundo seus interesses.

Sendo assim, vários aspectos precisam ser pontuados na relação entre mediadores e interagentes, tendo em vista não apenas o funcionamento das interações, mas, sobretudo, a potencialização das ações. Nesse contexto, a responsabilidade do mediador abrange etapas que se estendem des de a divulgação da disponibilidade de vagas até a assessoria durante e após as sessões, especialmente no que se refere à definição de objetivos específicos de aprendizagem e desenvolvimento da autonomia no processo por parte dos interagentes. 
Para a composição do grupo, os mediadores, inicialmente, abrem inscrições em suas instituições, de acordo com as vagas, calendário, horário, número de sessões, previamente acordados e agendados em seus respectivos laboratórios das instituições envolvidas; providenciam a divulgação por meio de diferentes recursos, tais como redes sociais, listas de e-mail, cartazes, para que os interessados se inscrevam; e, por fim, elaboram as listas de interagentes e seu pareamento. Nesse percurso, é muito importante observar que, além do convite e divulgação, é o mediador quem intervêm no incentivo à participação, bem como na conscientização quanto ao comprometimento com as atividades do projeto, em relação à assiduidade, pontualidade, entre outros aspectos. No caso da parceria UNESP - UNAM, a cada semestre são definidos oito encontros. Essas sessões de interação ocorrem uma vez por semana, com duração de uma hora e são sucedidas por sessões de mediação de aproximadamente quarenta minutos de discussão.

Antes de dar início às interações, é necessário preparar os interagentes com informações prévias pertinentes. Trata-se da sessão de orientação, definida por Telles (2015) como o momento em que se discute o que é aprendizagem em tandem e quais são seus princípios, tais como, autonomia, reciprocidade e separação das línguas, bem como se definem as estratégias básicas de aprendizagem de língua e comportamentos para esse processo; tais informações são dadas pelo professor mediador.

Portanto, as orientações abrangem tanto as questões mais técnicas quanto as informações sobre a estrutura, funcionamento e objetivos das interações em teletandem. Nesse momento, também pode ser sugerida aos interagentes uma lista de temas, conforme acordados previamente entre os mediadores. É importante ressaltar, no entanto, que os temas são apenas sugeridos inicialmente e, ao longo das interações, o mediador pode intervir indicando aos participantes que definam suas escolhas com seus pares, segundo as especificidades e os interesses de cada um, o que favorece o desenvolvimento dos princípios da autonomia e reciprocidade em teletandem.

Durante as sessões de interação, os mediadores participam na condução do processo, pois são eles que auxiliam e controlam o pareamento; dão instruções quanto ao uso do aplicativo skype (ou outros) e suas respectivas ferramentas, tais como, o compartilhamento de telas, dicionários virtuais, chat para registro e verificação ortográfıca; verificam o funcionamento dos computadores e acessórios; indicam aos interagentes o momento em que devem fazer a troca do idioma, de forma a que ambos tenham um bom aproveitamento da sessão. Nesse último aspecto, é importante observar que a primeira parte da sessão, em geral, é mais produtiva; assim sendo, é conveniente indicar o revezamento quanto à língua em que se começa a interação e cabe ao mediador também atentar-se para isso em orientações com seu grupo. A conscientização quanto à importância dos estudantes estarem presentes em cada uma das sessões agendadas e no cumprimento dos horários também é de responsabilidade do mediador. 
E, finalmente, após as sessões de interação, temos a sessão de mediação (TELLES, 2015) mais especificamente definida, conforme já destacamos anteriormente. Nesse caso, temos observado que a intervenção do mediador é extremamente necessária e, nesse momento, fica mais evidente a preferência por um profissional das línguas (o professor) para intermediar esse processo. Por constituir-se como um contexto autêntico de comunicação, o teletandem pode facilmente ser conduzido como um simples "momento de conversa" e os objetivos de aprendizagem acabam diluídos na interação. Entendemos que esse simples "momento de conversa" por si só pode favorecer a aprendizagem de línguas, tendo em vista uma perspectiva sociointeracionista da linguagem, que prevê o entendimento da língua como prática social (VYGOTSKY, 1991). No entanto, se definimos objetivos de aprendizagem, conforme previstos no teletandem, esse contexto pode tornar-se muito mais profícuo.

E nisso consiste o papel desse mediador, que pode, nesse momento e lugar, intervir estimulando a reflexão e conscientização, por parte dos interagentes, quanto à necessidade de definir objetivos específicos de aprendizagem, quer sejam eles relacionados aos conteúdos linguísticos (gramática, léxico, expressões idiomáticas etc.) ou aos aspectos interculturais (práticas sociais, comportamentos etc), bem como vinculados às estratégias de ensino e aprendizagem em concordância com seus parceiros de interação e estratégias para superar eventuais dificuldades. Nesse aspecto, reiteramos a importância do teletandem como contexto de reflexão sobre o processo de aprender e de ensinar línguas e, portanto, uma experiência única na formação de professores:

[...] acreditamos que o teletandem institucional representa para os cursos de formação de professores de línguas um espaço em que o discente dialoga com os conhecimentos de seus interlocutores e também com seus próprios conhecimentos. Configura-se como um cenário deflagrador de reflexões que potencializam e auxiliam na construção de saberes empíricos, teóricos e metodológicos importantes para o fortalecimento de sua identidade como professor, aqui, mais especificamente de espanhol/LE. (CARVALHO; MESSIAS, 2017, p. 72).

Em relação às questões interculturais, ainda, dada a especificidade do teletandem, é também fundamental conduzir a reflexão de modo a que as diferenças e comparações socioculturais possam de fato favorecer a compreensão de outras culturas e não reforçar preconceitos com base em estereótipos. Sobre as questões culturais que emergem no teletandem há, inclusive, uma série de trabalhos recém-publicados, tais como: Zakir (2015); Costa (2015); Andreu-Funo (2015); Salomão (2012). O trecho a seguir, extraído de uma gravação da sessão de mediação, ilustra como as comparações ocorrem facilmente nesse contexto e o mediador ( $M$ ) deve também atentar-se a isso, de modo a estimular as experiências e o aprendizado intercultural: 
(01) B: Mas foi interessante também a conversa com ela, porque o primeiro parceiro que eu fiz estava me falando da comida mexicana, que tudo eles colocam pimenta.

M: Mas eu também ponho pimenta em tudo e sou brasileira, risos...

B: Aí eu perguntei pra ela se realmente é comum, ela disse que sim, eles colocam na melancia, na manga, na maçã.

A2: Mas eles têm uma pimenta específica pra colocar na fruta.

A3: É diferente.

B: Ela me explicou que chama chile, ahh... explicou tudo lá como que faz o processo, não lembro exatamente mas é essa específica que eles colocam.

Em todo esse processo até aqui descrito, o mediador pode ainda intervir criando e gerenciando atividades ou tarefas ao longo do desenvolvimento das sessões de interação, as quais contribuem ainda mais para potencializar a aprendizagem. Em outras parcerias, tem sido muito comum a produção dos diários de interação (reflective journals, THORPE, 2004 apud SALOMÃO; EVANGELISTA, 2017 no prelo ou learning diaries, ARANHA; CAVALARI, 2017, no prelo) os quais são compartilhados e podem constituir não apenas dados de pesquisa, mas instrumentos para que o mediador avalie melhor todo o processo, suas implicações no ensino e aprendizagem de línguas e as possíveis dificuldades. Além dos diários, tem sido uma prática também estimular a troca de textos escritos entre os interagentes, os quais são mutuamente corrigidos.

\section{Mediação de teletandem entre línguas próximas (português/ espanhol): interface entre mediadores, interagentes e o processo de ensino e aprendizagem}

Um dos princípios da aprendizagem em tandem é não misturar as línguas; por essa razão, numa sessão de interação o tempo para cada idioma deve ser dividido igualmente. Esse princípio prático tende a promover o compromisso do aprendiz com a tarefa e com seu aprendizado (TELLES, 2009).

No caso de interações português/espanhol, temos observado, no entanto, que é muito comum que as línguas se misturem em alguns momentos, devido à proximidade e relativa possibilidade de intercompreensão. Quando isso se dá de forma consciente, para fins de contraste, pode contribuir para o aprendizado, conforme observa Benedetti $(2013$, p. 80):

Embora a mistura das línguas fira um dos princípios da aprendizagem em regime de tandem, ou seja, o uso separado das línguas de aprendizagem, o confronto entre as línguas/culturas durante a 
comunicação dialógica pode contribuir significativamente para o entendimento não só do funcionamento da língua como também dos valores que permeiam os significados dessa língua em contraste com a outra.

É o que observamos, por exemplo, no trecho a seguir, no qual o brasileiro narra que, após ser corrigido por seu parceiro, passa a entender o uso adequado das formas de tratamento em espanhol, em seu contraste tão marcado em relação ao uso na língua portuguesa.

(02) M: E você conseguiu falar mais em relação à semana passada?

SS: Sim, na semana passada, eu tava fazendo muita confusão porque eu comecei a misturar português, eu acho que estava meio nervosa e comecei a misturar português com espanhol, então eu tava... porque usted pra eles é como um tratamento formal, né? Então a todo momento eu não conseguia falar o tú, eu falava o usted e daí ele me corrigiu, porque seria como se eu estivesse falando senhor né e tal. Daí hoje eu já falei o tú, daí ele até falou que eu falei melhor, consegui falar mais.

Quando, porém, isso não ocorre, é necessário que os mediadores interfiram no acompanhamento e supervisão das interações, com o fim de evitar fossilizações e a enganosa sensação de competência comunicativa plena tão comum na aprendizagem de espanhol/LE por lusofalantes ou de português/LE por hispanofalantes. Dessa forma, podemos destacar que a modalidade de Teletandem Institucional em grupos tem favorecido esse acompanhamento, conforme já vimos discutindo:

[...] no caso da interação português/espanhol, as fronteiras entre as línguas, como vimos, nem sempre são tão evidentes, em especial, se se trata de aprendizes iniciantes. Dessa forma, acreditamos, mais uma vez, que a presença e a supervisão de um professor mediador sejam importantes para que os participantes possam obter um melhor aproveitamento nesse processo. O professor mediador pode, em seu trabalho de monitoração, observar e avaliar as interações, e, dessa maneira, intervir ajudando seus alunos a observarem tais ocorrências, assim como as marcas de sua interlíngua, bem como a de seu parceiro. (RAMOS, CARVALHO e MESSIAS, 2013, p. 17).

Esse aspecto tem sido um grande diferencial nessa modalidade de teletandem, especialmente entre as interações português/espanhol que, por sua singularidade, permitem certo grau de intercompreensão entre os pares. 0 trecho a seguir exemplifica, 
na mediação, a interferência da professora (mediadora - $M$ ) e de outros colegas em relação à delimitação de períodos para conversar em uma e outra língua.

(03) A2: Então hoje vocês tiraram vantagem...

A3: Porque semana passada foi em português.

M: Combina de sempre alterar pra vocês não ficarem em desvantagem, porque quando você fala primeiro sua língua alvo você tem uma vantagem de pique, de tempo, tema, de tópico de assunto.

J: É porque é sempre assim, você começa a falar do espanhol, eles respondem em português se você não cutucar a falar espanhol eles não mudam de língua.

M: tem que mudar.

Com a possibilidade de intercompreensão, os interagentes "acomodam-se" cada qual utilizando sua língua materna. A intervenção dos mediadores, aqui, se faz imprescindível para que os participantes se sintam desafiados a arriscarem-se na língua estrangeira, a comunicarem-se por meio dela, ainda que com as dificuldades inerentes a esse processo, segundo os objetivos e princípios delineados para a aprendizagem no contexto teletandem.

Como um território em que as diferenças nem sempre são perceptíveis, é o mediador, nesse caso, o professor de língua espanhola/LE e/ou professor de língua portuguesa/LE, quem pode indicar, a partir de sua observação no acompanhamento e supervisão das interações, as possíveis dificuldades e estratégias para superá-las.

Com relação a esse aspecto, evidentemente, entendemos que as interações em teletandem podem ser norteadas por objetivos diversos. Entretanto, considerando a especificidade da parceria aqui considerada, em que temos de um lado aprendizes de língua espanhola em contexto de formação de professores e, de outro, aprendizes de português para fins específicos de trabalho, se faz necessário atentar-se para esse fato com maior cuidado, com o objetivo claro de promover a proficiência e o conhecimento linguístico que aqui são requeridos. Conforme já pontuamos, anteriormente:

Embora, em princípio, possamos aceitar as manifestações dessa interlíngua (como resultado natural desse processo), é necessário saber que uma coisa é reconhecer sua existência; outra, muito diferente, é levar os alunos a assumirem o estudo do português/ LE e do espanhol/LE de forma a superá-la e a não se contentarem com a mera possibilidade de atender às necessidades primárias de comunicação, por meio do "portunhol" que, em geral, está longe 
de qualquer forma usual de expressão na língua-meta (CELADA; RODRIGUEZ, 2004 apud BRASIL, 2006). (RAMOS; CARVALHO; MESSIAS, 2013, p. 18).

\section{Considerações finais}

Neste trabalho, buscamos explicitar o processo de mediação por meio da descrição do papel do mediador no teletandem, em suas diversas perspectivas, as quais mobilizam um percurso de ações que são realizadas antes, durante e após o seu desenvolvimento; não apenas como uma sessão que acontece depois das interações. Com tal objetivo, sistematizamos a análise com base nas relações estabelecidas nas ações constitutivas desse processo, quais sejam: a interface entre mediadores e instituições; a interface entre mediadores; a interface entre mediadores e interagentes; e, finalmente, a mediação de teletandem entre línguas próximas (português/espanhol).

Observamos, sobretudo, que tal construção está intrinsecamente relacionada ao envolvimento dos mediadores em diferentes procedimentos em cada uma das etapas, as quais se iniciam com as primeiras negociações, perpassam toda a organização, o acompanhamento e culminam com a avaliação, em movimentos cíclicos, constantes e, por vezes, simultâneos/concomitantes. Com base em nossa discussão, destacamos a importância da constituição de todo esse processo de mediação para que haja êxito nas interações de teletandem, na modalidade institucional, desenvolvida em grupos.

Dessa forma, verificamos que a implementação do teletandem tem que partir desse professor/mediador impulsionado pelo desejo de promover contextos interativos, interculturais e tecnológicos, os quais são coerentes com uma concepção sociointeracionista de ensino e aprendizagem de línguas. A partir desse entendimento, 0 mediador precisa necessariamente estar comprometido com as instituições envolvidas, com seu parceiro também mediador e com seu grupo de interagentes.

Em relação ao contexto de línguas próximas, é importante ressaltar a importância da mediação no que se refere à atenção para os fatores de ordem linguístico-discursiva que estão presentes nesse contexto específico, especialmente quando se almeja que os alunos sejam capazes de identificar as diferenças entre essas línguas tão próximas, a fim de adquirirem proficiência linguística em ambos os idiomas. Nesse sentido, a mediação das sessões de teletandem é fundamental para o acompanhamento da evolução dos interagentes, conduzindo um monitoramento com vistas à conscientização crítica, percepção e reflexão sobre a realidade não apenas linguística, mas também intercultural. Por isso, as parcerias interinstitucionais e as pesquisas se tornam tão necessárias nesse processo. 
Vale salientar que nossa pretensão não foi estabelecer um guia ou receituário para a implementação do teletandem, mas apresentar uma discussão de caráter descritivo sobre os procedimentos necessários para o seu desenvolvimento de maneira a também contribuir para os estudos sobre o processo de mediação, neste contexto.

Sendo assim, embora nossa reflexão esteja circunscrita a um contexto específico, entendemos que este percurso delineado, em seus aspectos mais gerais, pode servir de aporte ou orientação para outras experiências, tanto no aprimoramento quanto na implementação da prática do teletandem em outros espaços educacionais, para instituição de novas parcerias e, consequentemente, para o fortalecimento do projeto.

\section{REFERÊNCIAS}

ANDREU-FUNO, L. Teletandem: um estudo sobre identidades culturais e sessões de mediação da aprendizagem. 2015. Tese (Doutorado em Estudos Linguísticos) - Instituto de Biociências, Letras e Ciências Exatas, Universidade Estadual Paulista "Júlio de Mesquita Filho", São José do Rio Preto, 2015.

ARANHA, S.; CAVALARI, S. M. S. A trajetória do projeto Teletandem Brasil: Da modalidade institucional não-integrada à institucional integrada. The ESPecialist, v. 35, n. 2, p. 183-201, 2014.

BENEDETTI, A. M. Teletandem. In: MAYRINK, M. F.; ALBUQUERQUE-COSTA, H. (org.). Ensino e aprendizagem de línguas em ambientes virtuais. São Paulo: Humanitas, 2013. p. 65-92.

CARVALHO, K. C. H. P.; MESSIAS, R. A. L. O teletandem no ensino e aprendizagem de espanhol/LE em contexto de formação inicial. Veredas - Revista de Estudos Linguísticos, v. 21, p. $60-74,2017$.

CARVALHO, K. C. H. P. de; MESSIAS, R. A. L.; DÍAS, A. M. Teletandem within the Context of closely-related languages: A Portuguese-Spanish interinstitutional experience. DELTA Revista de Documentação e Estudos em Linguística Teórica e Aplicada, v. 31, n. 3, p. 711-728, 2015.

CAVALARI, S. M. S.; ARANHA, S. Implications of teletandem integration into foreign language programs, 2017 [no prelo].

CHARMAZ, K. A construção da teoria fundamentada: guia prático para análise qualitativa. Tradução Joice Elias Costa. Porto Alegre: Artmed, 2009. 
COSTA, L. M. G. Performatividade e gênero nas interações em teletandem. 2015. Tese (Doutorado em Estudos Linguísticos) - Instituto de Biociências, Letras e Ciências Exatas, Universidade Estadual Paulista "Júlio de Mesquita Filho", São José do Rio Preto, 2015.

GARCIA, D. N. M. A logística das sessões de interação e mediação no teletandem com vistas ao ensino/aprendizagem de línguas estrangeiras. Estudos Linguísticos, v. 44, n. 2, p. $725-738,2015$.

RAMOS, K. A. H. P. Implicações socioculturais do processo de ensino de português para falantes de outras línguas no contexto virtual do Teletandem. Estudos Linguísticos, São Paulo, v. 42, n. 2, p. 731-742, maio-ago. 2013.

RAMOS, K. A. H. P.; CARVALHO, K. C. H. P.; MESSIAS, R. A. L. O ensino de português para hispanofalantes no contexto virtual do Teletandem. Portuguese Language Journal. Center for Latin American Studies at the University of Florida and the Latin American and Iberian Institute at the University of New Mexico, Fall 2013, v. 7, p. 1-23, 2013.

SALOMÃO, A. C. B. A cultura e o ensino de língua estrangeira: perspectivas para a formação continuada no projeto teletandem. 2012. Tese (Doutorado em Estudos Linguísticos) Instituto de Biociências, Letras e Ciências Exatas, Universidade Estadual Paulista "Júlio de Mesquita Filho", São José do Rio Preto, 2012.

SALOMÃO, A. C. B.; EVANGELISTA, M. C. R. G. Mediation in teletandem: from face to face dialogue to dialogical reflective journals, 2017 [no prelo].

TELLES, J. A. Learning foreign languages in teletandem: Resources and strategies. DELTA - Revista de Estudos em Linguística Teórica e Aplicada, v. 31, n. 3, p. 651-680, 2015.

TELLES, J. A. (org.). Teletandem: um contexto virtual, autônomo e colaborativo para aprendizagem de línguas estrangeiras no século XXI. Campinas: Pontes, 2009.

TELLES, J. A.; VASSALO, M. L. Teletandem: uma proposta alternativa no ensinoaprendizagem assistidos por computadores. In: TELLES, J. A. (org.). Teletandem: um contexto virtual, autônomo e colaborativo para aprendizagem de línguas estrangeiras no século XXI. Campinas: Pontes, 2009.

TELLES, J. A.; VASSALO, M. L. Foreign language learning in-tandem: Teletandem as an alternative proposal in CALLT. The ESPecialist, São Paulo (PUC), v. 27, n. 2, p. 189-212, 2006. 
VYGOTSKI, L. S. A formação social da mente. Tradução José Cipolla Neto. 7. ed. São Paulo: Martins Fontes, 2007.

VYGOTSKI, L. S. Pensamento e Linguagem. São Paulo: Martins Fontes, 1991.

ZAKIR, M. A. Cultura e $(m)$ telecolaboração: uma análise de parcerias de teletandem institucional. 2015. Tese (Doutorado em Estudos Linguísticos) - Instituto de Biociências, Letras e Ciências Exatas, Universidade Estadual Paulista "Júlio de Mesquita Filho", São José do Rio Preto, 2015. 